\title{
Recent Developments in Molecular Changes Leading to Alzheimer's Disease and Novel Therapeutic Approaches
}

\author{
Vijaya B. Kumar \\ VA Medical Center and St. Louis university Health Sciences Center, St. Louis, MO
}

USA

\section{Introduction}

Alzheimer's disease (AD) is a debilitating progressive neurological disease affecting significant number of individuals above the age of 65 years and even those who are as young as 30 years, around the globe. According to the Alzheimer's Association 2011 facts and figures report, Alzheimer's is the sixth leading cause of death and approximately 5.4 million people age 65 and older suffer from Alzheimer's disease in USA alone. Of all Americans over the age of 65, one out of every eight has AD. As the age advances, the risk of developing $\mathrm{AD}$ increases to as much as $47-50 \%$ by the age of 85 . Risk is even greater if both parents suffer the disease (Bachman et al, 1992). Two types of AD have been described. The sporadic form of $\mathrm{AD}$ is a general deterioration of intra-neuronal contact without any association to any genetic element. Familial AD (FAD) on the other hand is associated with mutations in amyloid precursor protein (APP) on chromosome 21 (Goates A.M et al, 1991), apolipoprotein E gene on chromosome 19 (Cedazo-Minguez \& Cowburn, 2001), presenilin 1 (PS1) on chromosome 14 (Sudoh et al, 1998), and presenilin 2 (PS2) on chromosome 1 (Jayadev et al, 2010). In addition, high phosphorylation that results in tangle formation is also attributed to mutations in the gene of microtubule associated protein Tau, located on chromosome 17 (Hanger et al, 1992). Among these, deposition of amyloid is widely accepted as the leading cause of AD. Although, amyloid plaque formation was observed in AD brains as early as 1907 (Alzheimer et al, 1995), it was only recently the toxicity (Yankner \& Lu, 2009; Yankner et al, 1990) and the contents (Tokutake, 1988; Vital, 1988; Pardridge et al, 1987) have been established. It has been a common observation in several investigations that a single or multiple mutations in any of these proteins alone can affect the performance of other proteins resulting in neurodegeneration. Each mutation in any single protein may differentially affect its function. Therefore, some of the mutations have more drastic consequences than others such as a quintessential mutation in PS2 described by Yu (Yu et al, 2010). In addition some of the mutations appear to cause greater harm than the others by shutting down a whole complex of protein activity such as specific presenilin 1 mutation (Heilig et al, 2010), suggesting that lethality and onset of AD is not a simple process. That said, the converse also appears to be true. That is, if the damage of any one of the affected proteins is reversed, it may be sufficient to alleviate the distress caused by the disease process (Kumar et al, 2000a). In light of the fact that reversal of the changes observed due to 
or as a consequence of $\mathrm{AD}$ in any one or two proteins may have beneficial effects has opened a possibility to target these proteins to develop therapeutic agents inter alia (Tokutake, 1988; Vital, 1988; Pardridge et al, 1987; Lee, 2002; Morley et al, 2002; Okura \& Matsumoto, 2007; Ohno, 2006; Schenk et al, 1999; Roggo, 2002; Evin et al, 2006; Hussain et al, 2007; Thompson et al, 2005; Kumar et al, 2000a; Santacruz et al, 2005; Kumar et al, 2000b). Despite so many targets for the development of agents that may alleviate the symptoms or even cure the disease, the available products to treat the disease are marginal.

Among various approaches that are made to reduce or enhance any of the affected proteins during $\mathrm{AD}$, this chapter deals with regulating some of these proteins by antisense oligonucleotide technology developed in my laboratory.
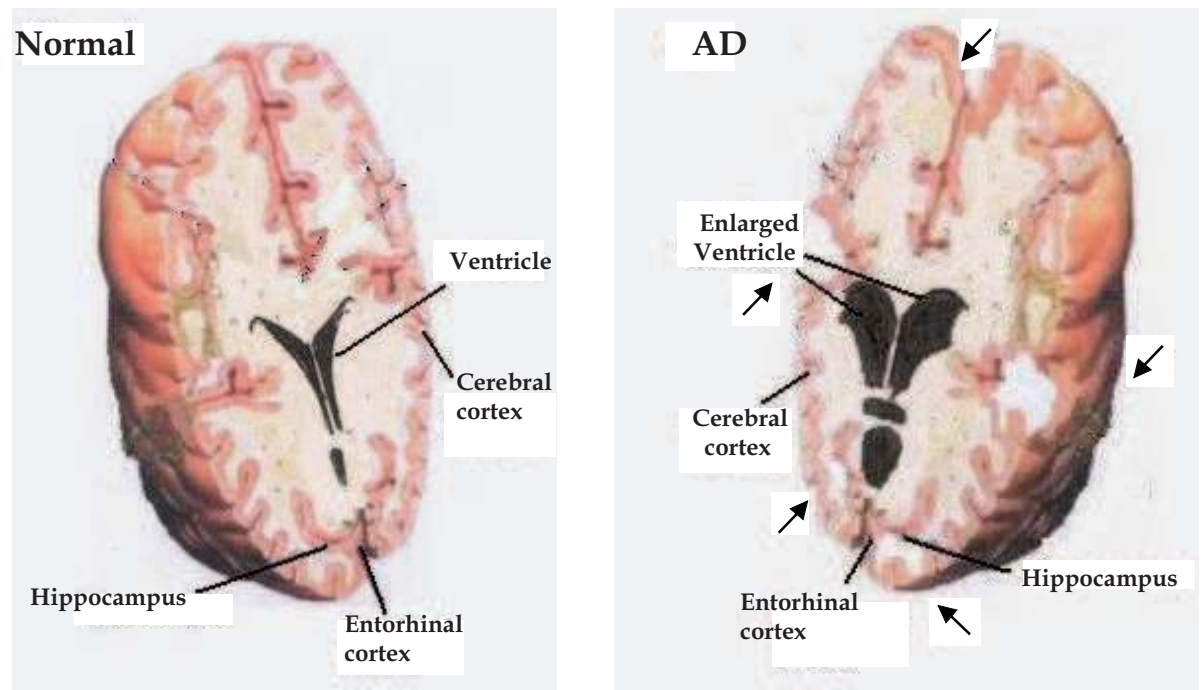

Fig. 1. Cartoon of normal and AD brains. In AD, there is overall shrinkage of the brain and ventricular enlargement. Arrows indicate some changes. The morphology of AD brain itself suggests that the disease is more complex involving multiple factors

\section{Areas of the brain affected in AD}

There are two major changes that can be observed in the brain upon the onset of AD. The morphological appearance of affected brain is significantly different compared to a normal brain due to the shrinkage of several areas of the brain and enlargement of the ventricles (Fig. 1). This shrinkage of some areas and enlargement of others in AD brain are dramatically different from the changes in cerebral cortex of a normal brain that occur due to normal aging. The cerebral cortex is the outer surface of the brain. It is responsible for all intellectual functioning. Although we find the effect on the overall brain being affected both in size and biology in $\mathrm{AD}$, mostly memory associated regions such as hippocampus (Puolivali et al, 2002), amygdala and septum show considerable degeneration in AD which also have shown an increased amounts of amyloid precursor protein (APP) (Kumar et al unpublished). Atrophy of the parietal and temporal lobes is observed in AD. Secondly, AD is characterized by the presence of numerous senile plaques and neurofibrillaray tangles 
(Chen \& Fernandez, 1999; Goedert \& Crowther, 1989). AD is associated with disorientation, loss of language and memory due to these changes. The memory associated region, mostly hippocampus suffers a progressive neuronal dysfunction and denigration of the neurons (Gibson, 1987). For this reason, my laboratory concentrated on the hippocampal areas in an animal model of AD (Kumar et al., 1999). It has been shown that increase in hippocampal APP correlates with memory loss in mice that exhibit early loss of memory (Morley et al., 2000). While the cortex, and the memory centers show physical and biochemical changes, the overall brain itself shows a shrinkage and enlargement of the ventricles. This may be due to the drastic changes in the membrane fluidity which follows the changes in the fatty acid composition as observed by Kumar et al (Kumar et al, 1999) in a senescence accelerated mouse brain. The histological features of $\mathrm{AD}$ in the brain are well characterized and three major hypotheses are currently in vogue for pharmaceutical agent development to combat this disease. The earliest hypothesis proposes a deficiency in cholinergic signaling. This is attributed to be the primary cause of initiation of the disease. The second hypothesis suggests that Tau protein alone or in combination with amyloid beta fragment begin the neuronal tangles and loss neuronal communication that initiate the disease. Thirdly APP is aberrantly processed resulting the plaque formation. Currently there is no clear accepted hypothesis for the initiation of AD. While current therapeutic agents are based on the first hypothesis, vigorous research to develop novel agents to combat the disease in many institutions, including my laboratory, is dependent on the amyloid beta hypothesis. This hypothesis provides several molecular targets to develop agents which may alleviate the disease symptoms, even though one cannot claim that they serve as preventive drug therapies. Therefore, it is essential to study in depth the molecular factors that are either the cause or manifestation of the disease to develop preventive or totally disease curing drugs.

\section{Molecular factors attributed to the manifestation of $A D$}

Deposition of amyloid plaques in AD patients was described as early as 1907 by Alzheimer -English translation (Alzheimer et al, 1995). Molecular analysis of the plaque (Pardridge et $a l, 1987)$ and understanding its toxicity is of recent origin (Yankner et al, 1990). The degeneration of neurons is attributed largely to a gradual accumulation of small molecular weight fragment derived from the proteolytic cleavage of APP (Blom \& Linnemann, 1992). This peptide fragment which varies in size from 38-43 amino acids is called amyloid beta protein (Aß). When this fragment is less than 42 amino acids, it is considered to be soluble and less harmful to the neuronal communications. At 42 amino acid level it can essentially precipitate and form plaques with increased propensity in the brain bringing down other $\mathrm{A} ß$ fragments and disrupt the cell-cell communication consequently causing the death of the neurons (Suzuki et al, 1994). As Aß is obtained by the cleavage of APP by the proteases called the secretases, these secretases are the targets for AD therapy (Hendriksen et al, 2002; Citron, 2000; Dewachter \& Van, 2002). These amyloid peptides are not independently translated although the B-peptide region starts with an ATG codon. No independent mRNA for this peptide thus far is isolated that opens an investigation to study a possibility of an independent translation for the $A B$ fragment(s). Therefore, it appears that the amount of this peptide is dependent on the amount of APP and the rate of elimination of A $\beta$ from the brain. PS1 and PS2 mutations and levels seem to affect the processing of APP thus increasing A $\beta$ concentrations. We measured PS1 levels and attributed this to the increased APP processing to cause early loss of memory in senescence accelerated mouse (SAMP8) (Kumar et al., 2009). 
We have also shown that one of the types of Tau increased with age in the SAMP8 mice (unpublished). Suppression of Tau in transgenic mice is shown to increase memory (Santacruz et al., 2005).

Increased risk of AD is associated with one or both apolipoprotein, APOE e4 (Green et al., 2002) alleles. However, the presence of APOE e4 alleles in itself is neither necessary nor sufficient to establish it as a diagnosis method of AD.

\section{Currently available therapies for Alzheimer's disease}

The clinical manifestation of Alzheimer's disease (AD) is dementia that typically begins with subtle and poorly recognized failure of memory and slowly becomes more severe and, eventually, incapacitating the individual. Other common findings include confusion, poor judgment, language disturbance, agitation, withdrawal, and hallucinations (Bacanu et al, 2005). Several strategies to counter these symptoms with various pharmaceutical agents are currently being used which essentially employ either acetylcholine esterase inhibition or glutamate pathway modification.

Various approaches are currently being taken to combat AD. The "cholinergic hypothesis" proposes that $\mathrm{AD}$ is initiated by a deficiency in the production of acetylcholine (an ester of acetic acid and choline, $\mathrm{CH}_{3} \mathrm{COOCH}_{2} \mathrm{CH}_{2} \mathrm{~N}\left(\mathrm{CH}_{3}\right)$. As this is an important neurotransmitter, early therapeutic agents were developed to increase or protect acetylcholine levels. Mode of action of Donepezil (commonly known as Aircept) is that it serves as an acetylcholine esterase inhibitor, thus acts by increasing the levels of acetylcholine. It is shown to be effective in mild cognitive impairments and Schizoprenia, and attention deficit disorder. Galantamine (commonly called Reminyl, Razadyne) is obtained from Narcissus pseudonarcissus, a tertiary alkaloid acts to inhibit acetyl choline esterase to increase the neurotransmitter, acetylcholine levels. This is a recently approved drug for AD treatment. Memantine is useful for many neurological disorders which includes AD. The mechanism of action of this drug is to act as an antagonist of the channels of N-methyl-d-aspartate (NMDA) receptors. The glutamate receptor subfamily is ubiquitously involved in several brain functions; therefore, this has a broader function for neurological disorders. The next available drug is rivastigmine tartrate (commonly known as Exelon) is a new generation acetylcholine esterase inhibitor. Lastly, tarcine (1,2,3,4-tetrahydro-5aminiacridine) is presumed to have several modes of actions to reverse the cognitive impairments. This is the earliest FDA approved drug for the treatment of AD. Its structure allows it to easily penetrate the cell membrane. The exact mechanism of its action is unknown. It enhances cholinergic function and several clinical studies with this drug have been done (Summers, 2006; Summers et al, 1989).

These medications, though beneficial, have not led to a cure. In all cases, they have served to only treat symptoms of the disease and have neither completely prevented nor reversed the disease. These results and other research have led to the conclusion that acetylcholine deficiencies may not be the direct cause but a result of neurodegeneration. Recently cholinergic effects have been proposed as a potential cause for the generation of the amyloidal plaques and tangles leading to neuroinflammation (Wenk, 2006).

Recent techniques of developing pharmacological agents for $\mathrm{AD}$ depend on the amyloid theory. Thus, the aim of the agents generated is to reduce the amount of Aß peptide formed. This is achieved, at least in the animal models, either by using some plant extracts or by the molecular targets that reduce the amount of secretases, or APP or Tau expression. In the 
herbal treatments, Chinese medicine leads the filed by offering several plant products for reducing the amyloid plaque formation. Danggui Shaoyao San (Hu et al, 2010) or Ginko biloba (Gold et al, 2003) are leading plant products in this area. Several large pharmaceutical companies are developing organic chemical agents that modulate the expression of proteins involved in the increase of plaque formation.

I will describe our approach that uses antisense oligonucleotide technology to achieve the same goal of prevention of plaque formation by reducing the amount of amyloid produced. This chapter essentially is dedicated to the approaches for the regulation of amyloid precursor protein (APP) and the proteases that generate plaque forming small molecular beta protein $(A B)$ using antisense oligonucleotides to specific regions of relevant mRNA(s) designed in my laboratory. Further, I will also describe a novel hybrid antisense technique which might open a new approach to regulate more than one message with a single antisense oligonucleotide. These hybrid antisense oligonucleotides have also been tested by my collaborators who confirmed their efficacy in animal models.

\section{Molecular techniques to counter the factors that induce AD symptoms}

At molecular level, several targets have been identified to develop new drugs. The approach of the large pharmaceutical agencies is to inhibit $\gamma$ secretase (Eli Lilly, Merk), blocking Receptor for advanced glycation end products (RAGE-by Pfizer), beta secretase- 1 block (CoMentis pharma), 5-HT1A receptor antagonish development (Wyeth etc labs) in addition to immunization against Aß protein (Melnikova, 2007).

In my laboratory we have altered the levels of APP, Tau PS1, $\gamma$ and $\beta$ secretases which have direct or indirect role in the generation of insoluble plaque forming $A \beta_{42}$ by using antisense oligonucleotide and siRNA technologies. We have shown their potency and beneficial effects in the cell culture and as well as animal models. We have successfully reversed the symptoms of memory loss and behavioral alterations (Banks et al, 2000; Kumar et al, 2000a). Even by reducing the levels of just APP, improvement to memory have been observed.

Recently we also developed what is named as hybrid antisense technology (unpublished) which has successfully affected more than one protein at molecular level. This novel technology will open new methods to possible successful therapies not only for AD but also other diseases, neurological or otherwise, which involves more than one gene.

\section{Antisense nucleotide technology}

Gene regulation can be achieved by several methods. Among these, ribozyme (Macpherson et al, 1999), small molecular weight interfering RNAs (siRNA/RNAi) (Koutsilieri et al, 2007) and antisense oligonucleotide technologies (Helene \& Toulme, 1990; Toulme et al, 1990) have been extensively studied. These techniques use a relatively simple concept that a complementary sequence can make a Watson-Crick base pairing with corresponding message thus preventing the translation. In the case of ribozyme which has a clover leaf structure, called as hammer head or hair pin, seeks out the targeted mRNA using complementary sequences, binds to mRNA and cleaves it, acting as a nuclease. RNA interference by SiRNAs and miRNAs are more complex. A dicer generates a double stranded structure of 21-23 nucleotides in length which gets separated and the complementary strand is amplified by RdRP (RNA dependent RNA polymerase). The single strand complexes with RISC (RNA induced silencing complex) and binds to target 
sequences and cleaves the mRNA which gets inactivated. Although the ribozyme and RNAi technologies are powerful techniques, their utility is largely confined to cell culture and in vitro studies due to the difficulties in their transport to specific sites without nuclease induced degradation. Antisense oligonucleotide technology on the other hand has more flexibility for regulation of messages both in vitro and in vivo. This technique utilizes a set of complementary oligonucleotides to a specific mRNA, to block its translation. The use of complementary deoxyribonucleotide sequences to halt mRNA translation has been described as early as 1977 (Paterson et al, 1977). In fact we have shown around the same time that RNA molecules and oligonucleotides could prevent RNA transcription in vitro (Kumar et al, 1977). Simplest method by which complementary sequences bind to a segment of a given mRNA block the translation of the mRNA is given in fig. 2. The mechanism of action of an antisense oligonucleotide is generally by RNase $\mathrm{H}$ cleavage of the double stranded region created by the complementary oligonucleotide that forms a hybrid with specific sequences on the mRNA. RNase $\mathrm{H}$ is rather ubiquitous enzyme. Alternatively, the hybrid formed by the complementary oligonucleotide may serve as a block to ribosome from proceeding to complete peptide synthesis. If the complementary sequences are made to $5^{\prime}$ un-translated region near or on the ribosome binding site, the ribosome would not even bind to initiate the translation or can be halted from movement. However, an internal antisense oligonucleotide generally works by RNase $\mathrm{H}$ mechanism, as assessed by the detection of incomplete mRNA molecules. Antisense oligonucleotide technology is not limited to preventing translation, but can be used to target the gene itself and prevent mRNA transcription thus preventing RNA splicing itself.

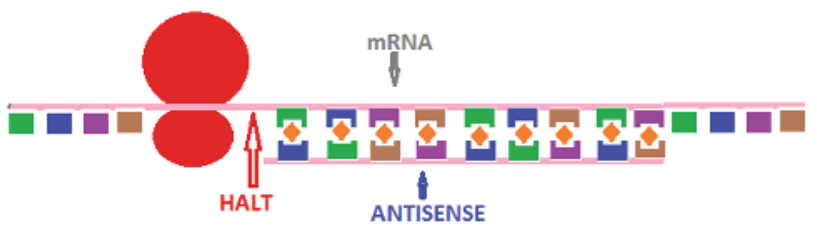

Fig. 2. A cartoon of complementary sequence (antisense) blockade of mRNA translation. This cartoon shows the steric hindrance of to the ribosome to prevent further completion of protein translation

There are several advantages in using antisense technology as opposed to RNAi technology. First of all, the antisense oligonucleotides are deoxy oligonucleotides, therefore, are more stable than RNA based antisense as in RNAi technology which uses ribonucleotide backbone in the complementary sequences. Therefore, it is more vulnerable to RNases. Secondly, the phosphate back bone and deoxyribose sugar can be modified in the antisense technology as these are made synthetically. This is done by substituting various other groups (Fig. 3) making the oligonucleotide more resistant to deoxyribonucleases. Thirdly, the quantity of antisense oligonucleotide can be manipulated so that the extent of mRNA regulation can be controlled. Further, sequences selected on the target mRNA, also give a handle to modulate the mRNA translation. In the case of RNA interference, such controls cannot be exerted. In the RNAi technology, the complementary sequences along with coding sequences need to be cloned into a vector, which generates the double stranded molecules continuously. Further, the double stranded molecule needs to be converted to single strand by cellular machinery to generate the antisense molecules which in turn inactivate the 
targeted message (Moazed, 2009). For all practical purposes, using deoxyoligonucleotides with altered sugar or phosphate bone appear to be more practical to modulate messages than SiRNA/RNAi techniques which have the same goal. However, the latter ones which have been shown to be more effective in cell cultures may become potent therapeutic agents once techniques to regulate their expression are developed. Currently, in a whole animal, including man, oligonucleotide technology may be more manageable to modulate gene activity. I generally used phophorothiated antisense oligonucleotides for in vivo studies (in the animal and cells) successfully (Kumar et al, 2000c; Kumar et al, 2001). We have shown that phosphorothiated antisense molecules did reverse the memory loss caused by aging or amyloid accumulation. Further, many laboratories used this technology against cancer (Dolnick, 1991), amyotrophic lateral sclerosis (ALS) (Smith et al, 2006), Ebola (Swenson et al, 2009; Enterlein et al, 2006), HIV Aids (Stein et al, 1989; Matsukura et al, 1989; Rossi et al, 2007), diabetes (Machen et al, 2004), Duchenne muscular dystrophy (Bremmer-Bout et al, 2004; Aartsma-Rus et al, 2004), Asthma (Nyce \& Metzger, 1997) etc. This technique has been applied for a variety of diseases including neurological diseases.

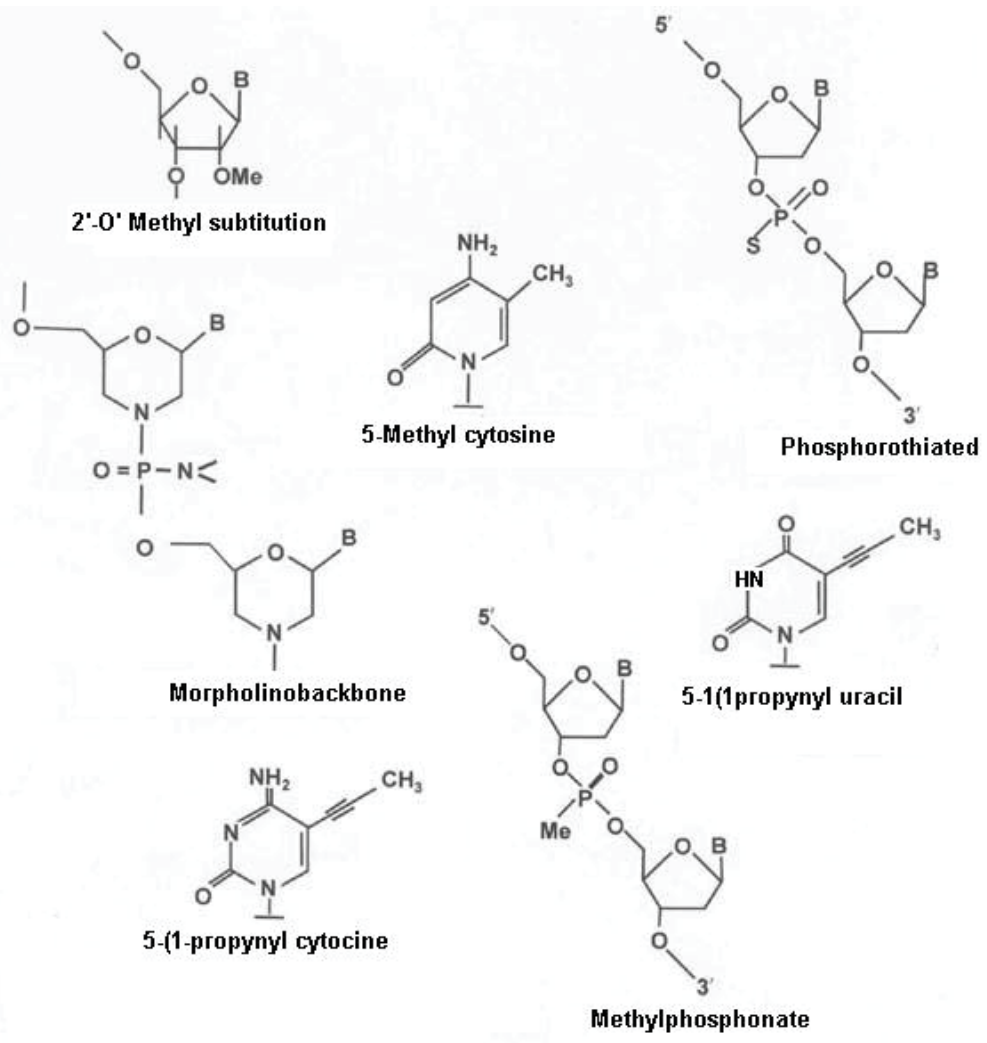

Fig. 3. Substitutions that make the oligonucleotides resistant to nuclease degradation. Figure shows currently available base substitutions that confer resistance to nuclease resistance to the oligonucleotide backbone 


\section{Uptake of antisense oligonucleotides}

Antisense oligonucleotides are easily taken up into the eukaryotic cells across cell membrane by active transport which is temperature dependent (Loke et al, 1989). However, the transport into neuronal cells is not a passive transport and needs help with external agents. Fig. 4 shows various agents that we used for transport across PC 12 cell line to test the efficacy of antisense oligonucleotides. In this experiments a 42 mer antisense against human APP. Amphotericin B was first used by us to transport DNA (Kumar et al, 1974) and later shown to be a valuable agent for the transport of oligonucleotides into 3T3 cells (Garcia-Chaumont et al, 2000). Using $\mathrm{CaCl}_{2}$ or Amphotericin B would cause some cell death if we cross concentrations above $1 \mathrm{mM}$ and $10 \mu \mathrm{M}$ respectively. In the figure we have used lower than these concentrations. DMSO concentration was 1\%. Lipid encapsulation transporter, lipofectamine did not cause any cell damage even at concentrations higher than suggested by the manufacturer.

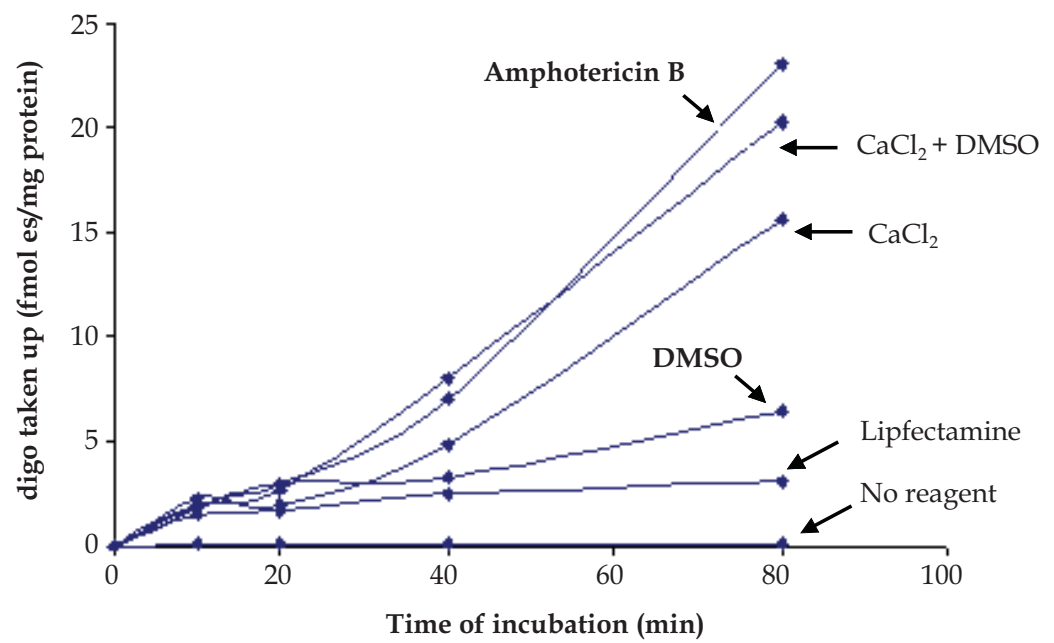

Fig. 4. Efficiency of transport of a 42 mer oligonucleotide into HTB 11 cells in the presence of various agents. The oligonucleotide was labeled with ${ }^{32} \mathrm{P}$ and purified by ethanol precipitation and tested for homogeneity on a $15 \%$ polyacrylamide gel. The cells were incubated with known amount of labeled oligonucleotide for specified times, washed, homogenized and counted. Notice that minimal concentrations of $\mathrm{CaCl}_{2}$ in combination with DMSO or Amphotericin B are of great advantage in the transport of oligonucleotides

When a mouse is administered an antisense oligonucleotide by any route, it can reduce the translation of corresponding mRNA. In the animal system, the neuronal cells have the ability to transport the oligonucleotide without the additional aid by cationic reagents. However, in both neuronal cells in culture and in the animal, the transport of oligonucleotide occurs by binding to specific receptor(s). When the cells were incubated with ${ }^{32} \mathrm{P}$ labeled oligonucleotide in the presence of $\mathrm{DMSO}+\mathrm{CaCl}_{2}$ as in fig. 5 and cell extracts were subjected gel retardation assay (Scott et al, 1994) by $12 \%$ polyacrylamide gel, we observed higher size bands suggesting its association with a protein(s) which may serve 
as receptors to transport the oligonucleotide (Fig. 5). Such an association is observed in the brain tissues of the animals which were administered the oligonucleotide. We have noticed that there are receptors in the brain that may be facilitating the transport of oligonucleotides.

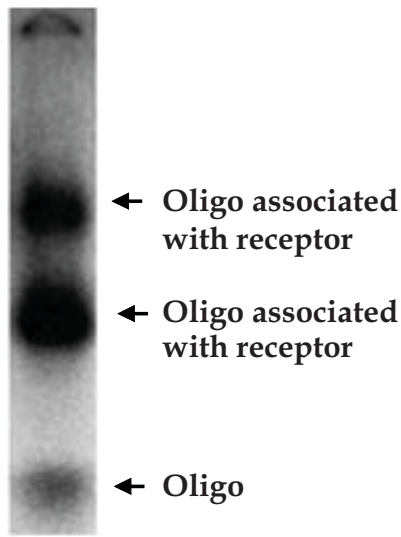

Fig. 5. Association of oligonucleotide with cellular receptor protein. HTB 11 human neuronal cells were incubated for 60 minutes and the cell extracts were run on $12 \%$ polyacrylamide gels in Trisborate buffer and subjected to autoradiography. Notice the association of majority of oligonucleotide with protein(s)

In the case of animals, the delivery of antisense oligonucleotides by three routes was tested. When the delivery was made by icv (intra crebrovascular), minimum amounts (as low as 60 $\mathrm{ng}$ /antisense oligonucleotides of 20-40 nucleotides) was very effective in reversing the loss of memory or acquisition. This is because most of the antisense oligonucleotide could be targeted to hippocampal area which is involved in memory. When an antisense oligonucleotide made against some sequences at A $\beta$ region of APP $\left(5^{\prime}\right.$ GGCGCCTTTGTTCGAACCCACATCTTCAGCAAAGAACACCAG - Kumar-US patent 6310048-2001) was administered by icv, its levels were considerably reduced (Kumar et al, 2000b). The transport of oligonucleotide though to a lesser extent occurs also by iv (intra venous) and reverses memory loss in mice (Banks et al, 2000). The transport into brain could also be achieved by oral or peritoneal routes (Kumar unpublished). For therapy, oral administration is most preferred. The distribution of orally and intraperitoneally administered oligonucleotide of 42 nucleotides is given in Figs. 6 and 7 respectively. Notice that by both routes of administration the percentage of the administered oligonucleotide recovered in the brain is same. But the distribution of the oligonucleotide in various organs is different. The behavioral studies are yet to be performed to quantify the efficacy of the oral or intraperitoneal administrations. But, the stability of the oligonucleotide was tested by extracting the oligonucleotide from these tissues by polyacrylamide gels. The oligonucleotide does undergo some degradation in all the tissues in spite of the fact that the oligonucleotide was phosphorothiated. However, what was extracted from brain did not seem to be degraded and is associated with a protein as it runs at a higher molecular weight than the monomer on polyacrylamide gels. 

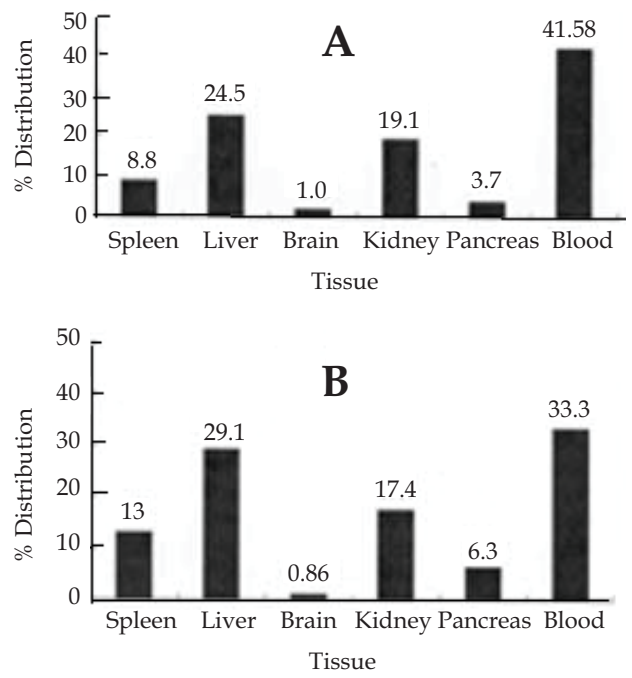

Fig. 6. Distribution short (20 mer-panel A) and long (42 mer-panel B) ${ }^{32} \mathrm{P}-$ labled oligonucleotide 4 hrs after oral administration in C57 black mice. 6 month old C57 black mice were administrated ${ }^{32} \mathrm{P}$-labled oligonucleotides and their distribution is similar irrespective of the size of the oligonucleotide
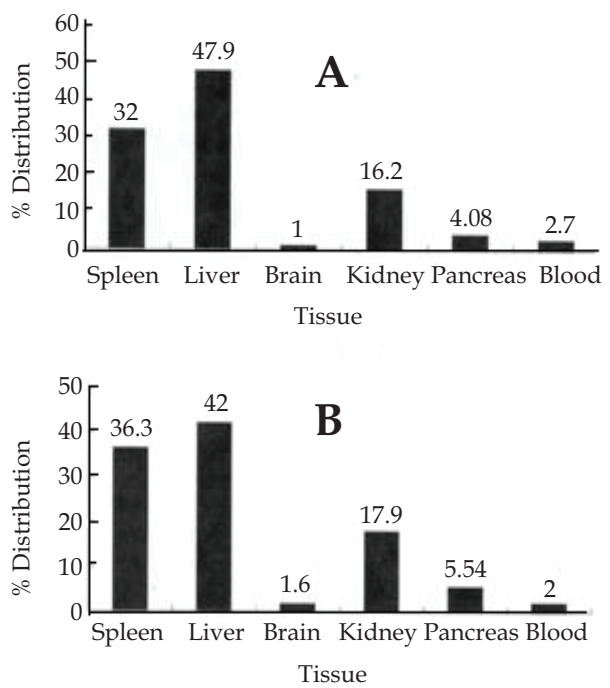

Fig. 7. Distribution short (20 mer-panel A) and long (42 mer-panel B) ${ }^{32 P-l a b l e d}$ oligonucleotide 4 hrs after intraperitoeneal administration in C57 black mice. 6 month old C57 black mice were administrated $32 \mathrm{P}$-labled oligonucleotides and their distribution was determinated as percent of a total/mg of protein. The distribution is similar irrespective of the size of the oligonucleotide 
If antisense oligonucleotides have become effective therapeutic agents, the efficacies of administration by different routes have to be established. Although, there is no evidence for any adverse effect in animal models used, in humans more experiments have to be performed to confirm that there will be no adverse effect. As oligonucleotides are natural products, adverse effects if any are likely to be minimal, if oral, nasal or intraperitoneal are the routes of administration.

\section{New antisense oligonucleotide technology to regulate multiple genes products with a single oligonucleotide}

Variety of neurological diseases including $\mathrm{AD}$, involve altered transcriptional and translational processes of more than one gene. If we consider Alzheimer's disease, a direct linkage exists for disease manifestation and altered expression of secretases, APP, apolipoprotein E, presenilins 1 and 2 and Tau phosphorylation. The changes in the expression of so many genes may be due to a single or multiple mutations in the corresponding genes or due to onset of disease. Therefore, these gene products are the rational molecular targets for the development of therapeutic agents. The results obtained by antisense molecules developed in my laboratory that modulated the expression of some of these proteins showed that this technology may be used to down regulate the specific mRNAs both in vivo and in vitro with surprisingly positive out come. In the case of methionine enkephalin, we have successfully used more than one antisense molecule to regulate the levels of this protein, as this protein has repetitive sequences (Banks et al, 2004). However, when two or more antisense oligonucleotides are used to regulate the messages, there is a high probability of developing anti nucleic acid antibodies (Isenberg et al, 2007;Hahn, 1998). In order to avoid such possibility, a technique where one single antisense oligonucleotide molecule can down regulate more than one mRNA is developed in my laboratory. It has been shown that even hexa and decamers have the ability to down regulate a targeted mRNA (Wagner, 1994;Wagner, 1995). Thus two phosphorothiated antisense oligonucleotides of ten nucleotide lengths against PS1 (5'TCTCTGTCAT) and APP (5'TGGGCAGCAT) mRNAs were constructed. A random oligonucleotide (5'GATCACGTAC) was used as control. Their ability to down regulate APP and PS1 proteins in COS 7 cells transfected with respective cDNAs in a co-transfected cell system was tested (Fig. 8, 9). Immunoblotting technique was used to quantify the expression (Kumar et al, 2009). In each of these cases there is $40-50 \%$ reduction in protein expression.

Based on the above observation A 20 mer hybrid antisense molecule was constructed with a combined sequence of anti APP (blue) and anti PS1 (Purple) (5' TGGGCAGCATTCTCTGTCAT). The hybrid consists of the first ten nucleotides are anti to APP message and the next ten are to anti to PS1 message. The fist 10 nucleotides, when binding to APP mRNA, there will be a $5^{\prime}$ over hang of 10 nucleotides and when it is binding to PS1 mRNA, it will have a $3^{\prime}$ over hang of the 10 nucleotides. Theoretically, such an over hang need not weaken the antisense blockade or RNase $\mathrm{H}$ degradation of the mRNA preventing it from translation. Random oligonucleotide (5'GATCACGTACACATCGACAC) along with the hybrid antisense described above was tested in a COS 7 cell transfected with the APP and PS1 cDNAs. The hybrid antisense molecule could effectively reduce the expression of both APP and PS1 almost as efficiently as individual 10 mers (Fig. 10) in 24 hours. The hybrid antisense oligonucleotides were successfully used in the animals to reverse the loss of memory in animal models of $\mathrm{AD}$ (Kumar et al unpublished). 

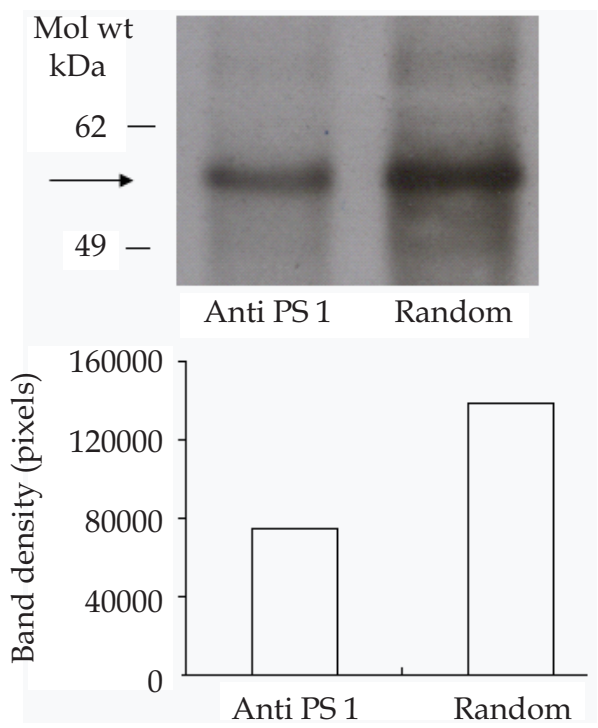

Fig. 8. Down regulation of PS1 with a 10 nucleotide antisense oligonucleotide in COS 7 cells. COS 7 cells were transfected with PS1 cDNA in pCDNA expression vector and a 10 mer antisense or a random oligonucleotide was co-transfected. Cells were grown for $24 \mathrm{hrs}$ and the $10 \mu \mathrm{g}$ of protein was subjected to immunoblotting. Lower panel gives band densities

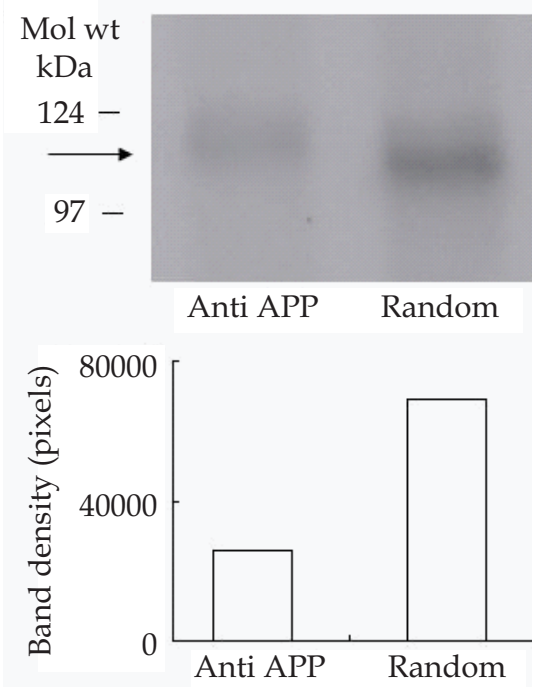

Fig. 9. Down regulation of APP with a 10 nucleotide antisense oligonucleotide in COS 7 cells. COS 7 cells were transfected with APP cDNA in pCDNA expression vector and a 10 mer antisense or random oligonucleotide was co-transfected. Cells were grown for $24 \mathrm{hrs}$ and the $10 \mu \mathrm{g}$ of protein was subjected to immunoblotting. Lower panel gives band densities 
Using a single antisense oligonucleotide molecule containing antisense sequences to two mRNAs to down regulate both mRNAs at the same time may have an advantage in avoiding possible auto antibody induction that may be caused if two different antisense molecules are administered at the same time. We have further extended this technique by using an oligonucleotide which has antisense oligonucleotide sequences against three mRNAs (PS1, APP and Tau).

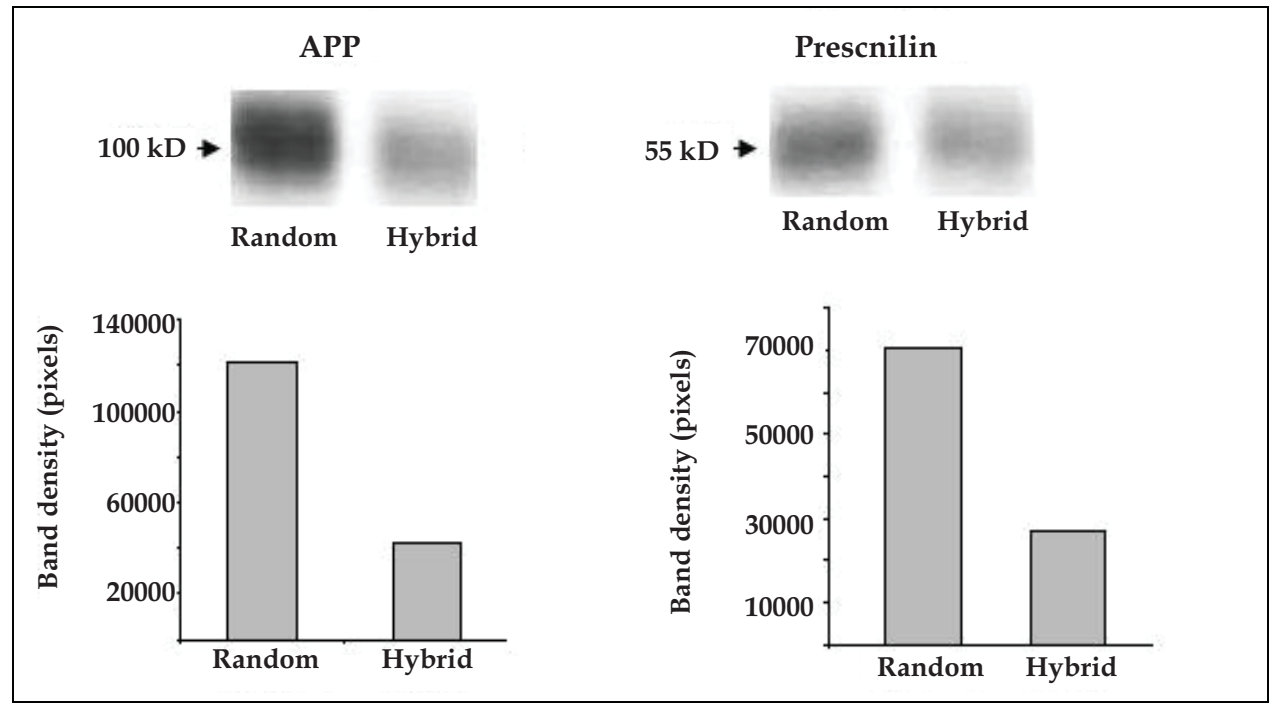

Fig. 10. Down regulation of APP and PS1 mRNAs by a hybrid antisense oligonucleotide. COS7 cells transfected with cDNAs of APP and PS1 were co-transfected with hybrid antisense oligonucleotide and a random control of 20 nucleotides. $24 \mathrm{hrs}$ after transfection, $10 \mu \mathrm{g}$ of cell extracts were subjected to immunoblotting. Notice the reduction of protein expression in antisense transfected cells

Despite the fact that the antisense sequence for one of the messages is embedded in the middle of the oligonucleotide the tribrid antisense molecule thus generated down regulated the translational products of all the three targeted messages (data not given). This approach of one oligonucleotide to regulate multiple messages may serve as an invaluable tool in antisense technology. This would also offset the fear of developing autoimmunity.

\section{Conclusion}

The use of complementary oligonucleotides to prevent translation of a given message was described as early as 1977 (Paterson et al, 1977). Using small RNA or oligonucleotides to block transcription by RNA polymerases was described by Kumar et al in 1977 (Kumar et al, 1977). Popular use of complementary synthetic deoxyribonucleitides took another 20 plus years. For a variety of reasons such as the low cost synthesis of oligonucleotides, relative stability, ease of transport, reproducible down regulation of a specific message, relatively simple method for base modification to generate nuclease resistant backbone etc. made antisense technology against a disease state became more common. Extensive use of 
antisense oligonucleotides in a variety of diseases is not therapeutically ubiquitous after the advent of more powerful RNA interference technology. Various methods are being developed to achieve a viable transport of SiRNA, miRNA (micro RNA) or ShRNA (short hairpin RNA) for clinical use (Leng et al, 2009). In this technology also, to increase the stability of interfering RNAs, base modifications such as 2'-O-methyl or morpholino are being developed (Behlke, 2008;Robbins et al, 2009). Despite increasing the stability, and billions of dollars spent to develop the agents to down regulate mRNAs by RNA interference, still a targeted and controlled delivery of SiRNA is a far cry. In addition, a viral/bacterial vector usage, while attractive, regulation of the amount produced is difficult. Therefore, currently complementary oligonucleotide therapy is an attractive practical method.

In this article, a novel method is proposed where by more than one gene product may be regulated by a single complementary sequence is described. This procedure is a valuable tool in combating diseases where more than one gene product is shown to be affected due to disease manifestation or as the cause for the disease. This technique will be of great use due to the fact that possible autoimmunity against DNA will be less compared to administering more than one antisense oligonucleotide. It is possible to envisage that this hybrid technology be combined with the currently available SiRNA technology for effective down regulation of several messages at the same time. My laboratory is currently developing such possible products. Novel oligonucleotides that enhance one gene and reduce another are also being developed in my laboratory. Such structures will naturally have a tremendous potential as therapeutic agents, as any disease state is not only accompanied by over expression, but also involves decreased expression of one or more mRNAs. As for the delivery of such molecules in humans, I would suggest nasal delivery instead of oral, intravenous or intra peritoneal. Results of such delivery using an animal model is not presented here, but that route appeared be very effective in preliminary experiments. As oligonucleotides may be considered natural to the biological systems, the possible side effects by antisense delivery may be expected to be rather insignificant. In conclusion, although RNA interference by small molecular weight or micro RNA and ShRNA is of great importance, direct antisense oligonucleotide technology should not be completely ignored, particularly because of its simplicity and ease with which such interfering molecules can be synthesized and administered for relatively low cost. Further, the demand from the cellular machinery by synthetic oligonucleotide for their processing is minimal compared to RNA interference technology which requires dicer mechanism. A combinational therapy of RNA interference and the hybrid technology may also be speculated for an efficient therapeutic intervention of over/under produced transcription and translational products. Such molecules are contemplated and designed by me in my laboratory. A note in proof: Craft et al (Archives of neurology on line Sep. 2011) reported an effective intranasal insulin therapy for $\mathrm{AD}$ and mild cognitive impairments, which further suggests that nasal administration suggested in this article may be the ideal route of administration for neurological impairments.

\section{Acknowledgements}

The author wishes to acknowledge the critical reading by Dr. Vijaya Lakshmi. The laboratory work done by Mr. Mark Franko, only a small sample of which is presented in this article is invaluable. The cells used in culture were donated by Dr. Girdhar Sharma of 
Washington University of St. Louis, for which the author is grateful. Thanks are due to Elaine Kosick and Connie Young of the illustration department of VA medical Center, St. Louis, for some of the illustrations used in this manuscript. The help rendered by Tamly J. Farrar is gratefully acknowledged.

\section{References}

Aartsma-Rus,A., Janson,A.A., Kaman,W.E., Bremmer-Bout,M., van Ommen,G.J., den Dunnen,J.T., \& van Deutekom,J.C. (2004) Antisense-induced multiexon skipping for Duchenne muscular dystrophy makes more sense. American Journal of Human Genetics, 74, 83-92.

Alzheimer,A., Stelzmann,R.A., Schnitzlein,H.N., \& Murtagh,F.R. (1995) An English translation of Alzheimer's 1907 paper, "Uber eine eigenartige Erkankung der Hirnrinde". Clinical Anatomy, 8, 429-431.

Bacanu,S.A., Devlin,B., Chowdari,K.V., DeKosky,S.T., Nimgaonkar,V.L., \& Sweet,R.A. (2005) Heritability of psychosis in Alzheimer disease. American Journal of Geriatric Psychiatry, 13, 624-627.

Bachman,D.L., Wolf,P.A., Linn,R., Knoefel,J.E., Cobb,J., Belanger,A., D'Agostino,R.B., \& White,L.R. (1992) Prevalence of dementia and probable senile dementia of the Alzheimer type in the Framingham Study. Neurology, 42, 115-119.

Banks,W.A., Farr,S.A., Butt,W., Kumar,B.V., Franko,M., \& Morley,J.E. (2000) Delivery of antisense directed against amyloid beta across the blood-brain barrier: reversal of learning and memory deficits in mice overexpressing APP. Journal of Pharmacolgy and experimental therapeutics, 297, 1113-1121.

Banks,W.A., Kumar,V.B., \& Morley,J.E. (2004) Influence of ethanol dependence and methionine enkephalin antisense on serum endomorphin-1 and methionine enkephalin levels. Alcoholism: Clinical \& Experimental Research., 28, 792-796.

Behlke,M.A. (2008) Chemical modification of siRNAs for in vivo use. Oligonucleotides, 18, 305-319.

Bremmer-Bout,M., Aartsma-Rus,A., de Meijer,E.J., Kaman,W.E., Janson,A.A., Vossen,R.H., van Ommen,G.J., den Dunnen,J.T., \& van Deutekom,J.C. (2004) Targeted exon skipping in transgenic hDMD mice: A model for direct preclinical screening of human-specific antisense oligonucleotides. Molecular Therapeutics, 10, 232-240.

Cedazo-Minguez,A. \& Cowburn,R.F. (2001) Apolipoprotein E: a major piece in the Alzheimer's disease puzzle. Journal of Cellular \& Molecular Medicine, 5, 254-266.

Chen,M. \& Fernandez,H.L. (1999) The Alzheimer's plaques, tangles and memory deficits may have a common origin. Part V: why is Ca2+ signal lower in the disease? Frontiers in Bioscience, 4, 9-15.

Citron,M. (2000) Secretases as targets for the treatment of Alzheimer's disease. Molecular Medicine Today, 6, 392-397.

Dewachter,I. \& Van,L.F. (2002) Secretases as targets for the treatment of Alzheimer's disease: the prospects. Lancet Neurology, 1, 409-416.

Dolnick,B.J. (1991) Antisense agents in cancer research and therapeutics. Cancer Investigation, 9, 185-194. 
Enterlein,S., Warfield,K.L., Swenson,D.L., Stein,D.A., Smith,J.L., Gamble,C.S., Kroeker,A.D., Iversen,P.L., Bavari,S., \& Muhlberger,E. (2006) VP35 knockdown inhibits Ebola virus amplification and protects against lethal infection in mice. Antimicrobial Agents and Chemotherapy, 50, 984-993.

Evin,G., Sernee,M.F., \& Masters,C.L. (2006) Inhibition of gamma-secretase as a therapeutic intervention for Alzheimer's disease: prospects, limitations and strategies. CNS Drugs, 20, 351-372.

Garcia-Chaumont,C., Seksek,O., Jolles,B., \& Bolard,J. (2000) A cationic derivative of amphotericin B as a novel delivery system for antisense oligonucleotides. Antisense E Nucleic Acid Drug Development, 10, 177-184.

Gibson,P.H. (1987) Ultrastructural abnormalities in the cerebral neocortex and hippocampus associated with Alzheimer's disease and aging. Acta Neuropathologica, 73, 86-91.

Goates A.M, Hayens,A.R., \& Owens,M.J.e.a. Segregation of missense mutation in the amyloid precursor protein with familial Alzheimer's disease. Nature, 349, 704-706. 1991.

Goedert,M. \& Crowther,R.A. (1989) Amyloid plaques, neurofibrillary tangles and their relevance for the study of Alzheimer's disease. Neurobiology of Aging, 10, 405-6.

Gold,P.E., Cahill,L., \& Wenk,G.L. (2003) The lowdown on Ginkgo biloba. Scientific American, 288, 86-91.

Hahn,B.H. (1998) Antibodies to DNA. New England Journal of Medicine, 338, 1359-1368.

Hanger,D.P., Mann,D.M., Neary,D., \& Anderton,B.H. (1992) Tau pathology in a case of familial Alzheimer's disease with a valine to glycine mutation at position 717 in the amyloid precursor protein. Neuroscience Letters, 145, 178-180.

Heilig,E.A., Xia,W., Shen,J., \& Kelleher,R.J., III (2010) A presenilin-1 mutation identified in familial Alzheimer disease with cotton wool plaques causes a nearly complete loss of gamma-secretase activity. Journal of Biological Chemistry, 285, 22350-22359.

Helene,C. \& Toulme,J.J. (1990) Specific regulation of gene expression by antisense, sense and antigene nucleic acids. Biochimica et Biophysica Acta, 1049, 99-125.

Hendriksen,J.V., Nottet,H.S., \& Smits,H.A. (2002) Secretases as targets for drug design in Alzheimer's disease. European Journal of Clinical Investigation, 32, 60-68.

Hu,Z.Y., Liu,G., Yuan,H., Yang,S., Zhou,W.X., Zhang,Y.X., \& Qiao,S.Y. (2010) DangguiShaoyao-San and its active fraction JD-30 improve Abeta-induced spatial recognition deficits in mice. Journal of Ethnopharmacology, 128, 365-372.

Hussain,I., Hawkins,J., Harrison,D., Hille,C., Wayne,G., Cutler,L., Buck,T., Walter,D., Demont,E., Howes,C., Naylor,A., Jeffrey,P., Gonzalez,M.I., Dingwall,C., Michel,A., Redshaw,S., \& Davis,J.B. (2007) Oral administration of a potent and selective non-peptidic BACE-1 inhibitor decreases beta-cleavage of amyloid precursor protein and amyloid-beta production in vivo. Journal of Neurochemistry, 100, 802-809.

Isenberg,D.A., Manson,J.J., Ehrenstein,M.R., \& Rahman,A. (2007) Fifty years of anti-ds DNA antibodies: are we approaching journey's end? Rheumatology.(Oxford), 46, 1052-1056. 
Jayadev,S., Leverenz,J.B., Steinbart,E., Stahl,J., Klunk,W., Yu,C.E., \& Bird,T.D. (2010) Alzheimer's disease phenotypes and genotypes associated with mutations in presenilin 2. Brain, 133, 1143-1154.

Koutsilieri,E., Rethwilm,A., \& Scheller,C. (2007) The therapeutic potential of siRNA in gene therapy of neurodegenerative disorders. Journal of Neural Transmission. Supplementum, 72., 43-90.

Kumar,B.V., McMillian,R., Medoff,G., Schlessinger,D., \& Kobayashi,G.S. (1977) Mechanism of the inhibition by RNA of the RNA polymerases of Histoplasma capsulatum. Biochimica et Biophysica Acta, 478, 192-200.

Kumar,B.V., Medoff,G., Kobayashi,G., \& Schlessinger,D. (1974) Uptake of Escherichia coli DNA into HeLa cells enhanced by amphotericin B. Nature, 1974 250, 323-325.

Kumar,V.B., Farr,S.A., Flood,J.F., Kamlesh,V., Franko,M., Banks,W.A., \& Morley,J.E. (2000a) Site-directed antisense oligonucleotide decreases the expression of amyloid precursor protein and reverses deficits in learning and memory in aged SAMP8 mice. Peptides, 21, 1769-1775.

Kumar,V.B., Farr,S.A., Flood,J.F., Kamlesh,V., Franko,M., Banks,W.A., \& Morley,J.E. (2000b) Site-directed antisense oligonucleotide decreases the expression of amyloid precursor protein and reverses deficits in learning and memory in aged SAMP8 mice. Peptides, 21, 1769-1775.

Kumar,V.B., Farr,S.A., Flood,J.F., Kamlesh,V., Franko,M., Banks,W.A., \& Morley,J.E. (2000c) Site-directed antisense oligonucleotide decreases the expression of amyloid precursor protein and reverses deficits in learning and memory in aged SAMP8 mice. Peptides, 21, 1769-1775.

Kumar,V.B., Franko,M., Banks,W.A., Kasinadhuni,P., Farr,S.A., Vyas,K., Choudhuri,V., \& Morley,J.E. (2009) Increase in presenilin 1 (PS1) levels in senescence-accelerated mice (SAMP8) may indirectly impair memory by affecting amyloid precursor protein (APP) processing. Journal of Experimental Biology, 212, 494-498.

Kumar,V.B., Vyas,K., Buddhiraju,M., Alshaher,M., Flood,J.F., \& Morley,J.E. (1999) Changes in membrane fatty acids and delta-9 desaturase in senescence accelerated (SAMP8) mouse hippocampus with aging. Life Sciences, 65, 1657-1662.

Kumar,V.B., Vyas,K., Franko,M., Choudhary,V., Buddhiraju,C., Alvarez,J., \& Morley,J.E. (2001) Molecular cloning, expression, and regulation of hippocampal amyloid precursor protein of senescence accelerated mouse (SAMP8). Biochemistry and Cell biology, 79, 57-67.

Lee,V.M. (2002) Amyloid binding ligands as Alzheimer's disease therapies. Neurobiology of Aging, 23, 1039-1042.

Leng,Q., Woodle,M.C., Lu,P.Y., \& Mixson,A.J. (2009) Advances in Systemic siRNA Delivery. Drugs Future, 34, 721.

Loke,S.L., Stein,C.A., Zhang,H., Mori,A., Nakanishi,M., Subasinghe,C., Cohen,J.S., \& Neckers,L.M. (1989) Characterization of oligonucleotide transport into living cells. Proceedings of the National Academy of Sciences of the United States of America, 86, 34743478.

Machen,J., Harnaha,J., Lakomy,R., Styche,A., Trucco,M., \& Giannoukakis,N. (2004) Antisense oligonucleotides down-regulating costimulation confer diabetes- 
preventive properties to nonobese diabetic mouse dendritic cells. Journal of Immunology, 173, 4331-4341.

Macpherson,J.L., Ely,J.A., Sun,L.Q., \& Symonds,G.P. (1999) Ribozymes in gene therapy of HIV-1. Frontiers in Bioscience, 4, D497-D505.

Matsukura,M., Zon,G., Shinozuka,K., Robert-Guroff,M., Shimada,T., Stein,C.A., Mitsuya,H., Wong-Staal,F., Cohen,J.S., \& Broder,S. (1989) Regulation of viral expression of human immunodeficiency virus in vitro by an antisense phosphorothioate oligodeoxynucleotide against rev (art/trs) in chronically infected cells. Proc.Natl.Acad.Sci.U.S.A, 86, 4244-4248.

Melnikova,I. (2007) Therapies for Alzheimer's disease. Nature Reviews Drug Discovery, 6, 341342.

Moazed,D. (2009) Small RNAs in transcriptional gene silencing and genome defence. Nature, 457, 413-420.

Morley,J.E., Farr,S.A., \& Flood,J.F. (2002) Antibody to amyloid beta protein alleviates impaired acquisition, retention, and memory processing in SAMP8 mice. Neurobiology of Learning $\mathcal{E}$ Memory, 78, 125-138.

Nyce,J.W. \& Metzger,W.J. (1997) DNA antisense therapy for asthma in an animal model. Nature, 385, 721-725.

Ohno,M. (2006) Genetic and pharmacological basis for therapeutic inhibition of beta- and gamma-secretases in mouse models of Alzheimer's memory deficits. Reviews in the Neurosciences, 17, 429-454.

Okura,Y. \& Matsumoto,Y. (2007) Development of anti-Abeta vaccination as a promising therapy for Alzheimer's disease. Drug News \& Perspectives., 20, 379-386.

Pardridge,W.M., Vinters,H.V., Yang,J., Eisenberg,J., Choi,T.B., Tourtellotte,W.W., Huebner,V., \& Shively,J.E. (1987) Amyloid angiopathy of Alzheimer's disease: amino acid composition and partial sequence of a 4,200-dalton peptide isolated from cortical microvessels. Journal of Neurochemistry, 49, 1394-1401.

Paterson,B.M., Roberts,B.E., \& Kuff,E.L. (1977) Structural gene identification and mapping by DNA-mRNA hybrid-arrested cell-free translation. Proceedings of the National Academy of Sciences of the United States of America, 74, 4370-4374.

Puolivali,J., Wang,J., Heikkinen,T., Heikkila,M., Tapiola,T., van Groen,T., \& Tanila,H. (2002) Hippocampal A beta 42 levels correlate with spatial memory deficit in APP and PS1 double transgenic mice. Neurobiology of Disease., 9, 339-347.

Robbins,M., Judge,A., \& MacLachlan,I. (2009) siRNA and innate immunity. Oligonucleotides, $19,89-102$.

Roggo,S. (2002) Inhibition of BACE, a promising approach to Alzheimer's disease therapy. Current Topics in Medicinal Chemistry, 2, 359-370.

Rossi,J.J., June,C.H., \& Kohn,D.B. (2007) Genetic therapies against HIV. Nature Biotechnology, $25,1444-1454$.

Santacruz,K., Lewis,J., Spires,T., Paulson,J., Kotilinek,L., Ingelsson,M., Guimaraes,A., DeTure,M., Ramsden,M., McGowan,E., Forster,C., Yue,M., Orne,J., Janus,C., Mariash,A., Kuskowski,M., Hyman,B., Hutton,M., \& Ashe,K.H. (2005) Tau suppression in a neurodegenerative mouse model improves memory function. Science, 309, 476-481. 
Schenk,D., Barbour,R., Dunn,W., Gordon,G., Grajeda,H., Guido,T., Hu,K., Huang,J., Johnson-Wood,K., Khan,K., Kholodenko,D., Lee,M., Liao,Z., Lieberburg,I., Motter,R., Mutter,L., Soriano,F., Shopp,G., Vasquez,N., Vandevert,C., Walker,S., Wogulis,M., Yednock,T., Games,D., \& Seubert,P. (1999) Immunization with amyloid-beta attenuates Alzheimer-disease-like pathology in the PDAPP mouse [see comments]. Nature, 400, 173-177.

Scott,V., Clark,A.R., \& Docherty K. Protocols for Gene Analysis. Methods in Molecular Biology, 31, 339-347. 1994.

Smith,R.A., Miller,T.M., Yamanaka,K., Monia,B.P., Condon,T.P., Hung,G., Lobsiger,C.S., Ward,C.M., McAlonis-Downes,M., Wei,H., Wancewicz,E.V., Bennett,C.F., \& Cleveland,D.W. (2006) Antisense oligonucleotide therapy for neurodegenerative disease. Journal of Clinical Investigation, 116, 2290-2296.

Stein,C.A., Matsukura,M., Subasinghe,C., Broder,S., \& Cohen,J.S. (1989) Phosphorothioate oligodeoxynucleotides are potent sequence nonspecific inhibitors of de novo infection by HIV. AIDS Research and Human Retroviruses, 5, 639-646.

Sudoh,S., Kawamura,Y., Sato,S., Wang,R., Saido,T.C., Oyama,F., Sakaki,Y., Komano,H., \& Yanagisawa,K. (1998) Presenilin 1 mutations linked to familial Alzheimer's disease increase the intracellular levels of amyloid beta-protein 1-42 and its N-terminally truncated variant(s) which are generated at distinct sites. Journal of Neurochemistry, $71,1535-1543$.

Summers,W.K. (2006) Tacrine, and Alzheimer's treatments. Journal of Alzheimer's Disease, 9, 439-445.

Summers,W.K., Tachiki,K.H., \& Kling,A. (1989) Tacrine in the treatment of Alzheimer's disease. A clinical update and recent pharmacologic studies. European Neurology, 29 Suppl 3, 28-32.

Suzuki,N., Cheung,T.T., Cai,X.D., Odaka,A., Otvos,L.J., Eckman,C., Golde,T.E., \& Younkin,S.G. (1994) An increased percentage of long amyloid beta protein secreted by familial amyloid beta protein precursor (beta APP717) mutants. Science, 264, 1336-1340.

Swenson,D.L., Warfield,K.L., Warren,T.K., Lovejoy,C., Hassinger,J.N., Ruthel,G., Blouch,R.E., Moulton,H.M., Weller,D.D., Iversen,P.L., \& Bavari,S. (2009) Chemical modifications of antisense morpholino oligomers enhance their efficacy against Ebola virus infection. Antimicrobial Agents and Chemotherapy, 53, 2089-2099.

Thompson,L.A., Bronson,J.J., \& Zusi,F.C. (2005) Progress in the discovery of BACE inhibitors. Current Pharmaceutical Design., 11, 3383-3404.

Tokutake,S. (1988) [Biochemical and immunological properties of senile plaque amyloid]. [Japanese]. Nippon Ronen Igakkai Zasshi - Japanese Journal of Geriatrics, 25, 352-357.

Toulme,J.J., Verspieren,P., Boiziau,C., Loreau,N., Cazenave,C., \& Thuong,N.T. (1990) [Antisense oligonucleotides: tools of molecular genetics and therapeutic agents]. Ann.Parasitol.Hum.Comp, 65 Suppl 1, 11-14.

Vital,C. (1988) [Cerebral amyloid angiopathy]. [French]. Revue de Medecine Interne, 9, 12-17. 
Wagner,R.W. (1994) Gene inhibition using antisense oligodeoxynucleotides. Nature, 372, 333-335.

Wagner,R.W. (1995) The state of the art in antisense research. Nature Medicine, 1, 1116-1118.

Wenk,G.L. (2006) Neuropathologic changes in Alzheimer's disease: potential targets for treatment. Journal of Clinical Psychiatry, 67 Suppl 3, 3-7.

Yankner,B.A., Duffy,L.K., \& Kirschner,D.A. (1990) Neurotrophic and neurotoxic effects of amyloid beta protein: reversal by tachykinin neuropeptides. Science, 250, 279-282.

Yankner,B.A. \& Lu,T. (2009) Amyloid beta-protein toxicity and the pathogenesis of Alzheimer disease. Journal of Biological Chemistry, 284, 4755-4759.

Yu,C.E., Marchani,E., Nikisch,G., Muller,U., Nolte,D., Hertel,A., Wijsman,E.M., \& Bird,T.D. (2010) The N141I mutation in PSEN2: implications for the quintessential case of Alzheimer disease. Archives of Neurology, 67, 631-633. 


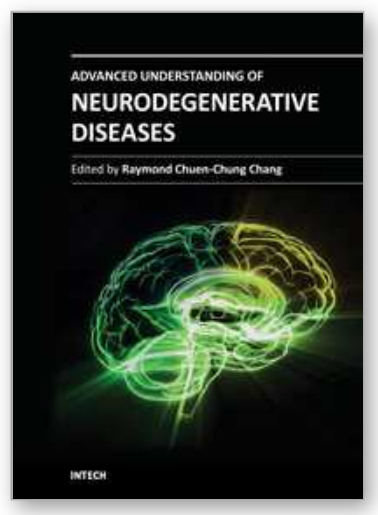

\author{
Advanced Understanding of Neurodegenerative Diseases \\ Edited by Dr Raymond Chuen-Chung Chang
}

ISBN 978-953-307-529-7

Hard cover, 442 pages

Publisher InTech

Published online 16, December, 2011

Published in print edition December, 2011

Advanced Understanding of Neurodegenerative Diseases focuses on different types of diseases, including Alzheimer's disease, frontotemporal dementia, different tauopathies, Parkinson's disease, prion disease, motor neuron diseases such as multiple sclerosis and spinal muscular atrophy. This book provides a clear explanation of different neurodegenerative diseases with new concepts of understand the etiology, pathological mechanisms, drug screening methodology and new therapeutic interventions. Other chapters discuss how hormones and health food supplements affect disease progression of neurodegenerative diseases. From a more technical point of view, some chapters deal with the aggregation of prion proteins in prion diseases. An additional chapter to discuss application of stem cells. This book is suitable for different readers: college students can use it as a textbook; researchers in academic institutions and pharmaceutical companies can take it as updated research information; health care professionals can take it as a reference book, even patients' families, relatives and friends can take it as a good basis to understand neurodegenerative diseases.

\title{
How to reference
}

In order to correctly reference this scholarly work, feel free to copy and paste the following:

Vijaya B. Kumar (2011). Recent Developments in Molecular Changes Leading to Alzheimer's Disease and Novel Therapeutic Approaches, Advanced Understanding of Neurodegenerative Diseases, Dr Raymond Chuen-Chung Chang (Ed.), ISBN: 978-953-307-529-7, InTech, Available from:

http://www.intechopen.com/books/advanced-understanding-of-neurodegenerative-diseases/recentdevelopments-in-molecular-changes-leading-to-alzheimer-s-disease-and-novel-therapeutic-approa

\section{INTECH}

open science / open minds

\section{InTech Europe}

University Campus STeP Ri

Slavka Krautzeka 83/A

51000 Rijeka, Croatia

Phone: +385 (51) 770447

Fax: +385 (51) 686166

www.intechopen.com

\section{InTech China}

Unit 405, Office Block, Hotel Equatorial Shanghai

No.65, Yan An Road (West), Shanghai, 200040, China 中国上海市延安西路65号上海国际贵都大饭店办公楼 405 单元

Phone: +86-21-62489820

Fax: +86-21-62489821 
(C) 2011 The Author(s). Licensee IntechOpen. This is an open access article distributed under the terms of the Creative Commons Attribution 3.0 License, which permits unrestricted use, distribution, and reproduction in any medium, provided the original work is properly cited. 